\title{
Self-employment, wage employment, and informality in a developing economy
}

\author{
John Bennett ${ }^{a}$ and Matthew D. Rablen ${ }^{b}$
}

${ }^{a}$ Department of Economics and Finance, Brunel University London, Uxbridge, UB8 3PH; and IZA, Bonn; e-mail: john.bennett@brunel.ac.uk

${ }^{b}$ Department of Economics and Finance, Brunel University London, Uxbridge, UB8 3PH; and IZA, Bonn; e-mail: matthew.rablen@brunel.ac.uk

\begin{abstract}
We construct a simple model incorporating various urban labour market phenomena obtaining in developing economies, and we give a diagrammatic formulation of the market equilibrium. Our initial formulation assumes an integrated labour market and allows for entrepreneurship, self-employment, and wage employment. We then introduce labour market segmentation. In equilibrium voluntary and involuntary self-employment, formal and informal wage employment, and formal and informal entrepreneurship may all coexist. We illustrate the model by an example calibrated on Latin American data, examining individual labour market transitions and implications of education/training and labour market policies.
\end{abstract}

JEL classifications: 017, J23

\section{Introduction}

Urban labour markets in developing economies exhibit considerable diversity, typically including substantial segments of both voluntary and involuntary self-employment and of formal and informal wage employment. In Latin America and the Caribbean, for example, Perry et al. (2007) find that on average, $24 \%$ of urban employment is informal self-employment and $30 \%$ is informal wage employment, and each of these segments have significant voluntary and involuntary elements. ${ }^{1}$ The aim of the present article is to formulate a simple model that incorporates all of these labour market states, as well as different types of entrepreneurship, and develop a diagrammatic analysis of market equilibrium. Some recent literature on informality based on search-and-matching theory also incorporates the

1 See Fields (2009) for a general discussion of the complexity of labour markets in developing economies and of approaches to modelling them. 
interaction of several of these labour market states (Albrecht et al., 2009; Margolis et al., 2012), but is rather complex and relies extensively on simulations to generate results.

In contrast to most of the theoretical literature on informality, we model in detail the supply as well as the demand side of the labour market. ${ }^{2}$ We assume that each agent can allocate his or her labour to one of three activities: self-employment, wage employment, or entrepreneurship (running a firm and providing wage employment to others). ${ }^{3}$ An agent is characterized in terms of two skills, $Y$ and $Z$, where, loosely speaking, $Y$ is the ability to produce and sell an output, and $Z$ is managerial ability. Success as a self-employed worker would depend on the amount $y$ of skill Y possessed; but following the Lazear (2005) 'jackof-all-trades' formulation, success as an entrepreneur would depend on applying both skills together, specifically, on the value of $\min (y, z)$, where $z$ is the amount of $Z$ the agent possesses. In wage employment, however, everyone is assumed to be equally able. ${ }^{4}$

We develop two versions of the model. First, in our benchmark case, we assume that the market for wage employment clears, so that all labour states are 'voluntary'. This is useful for expositional purposes, providing the groundwork for the second version of the model, in which we assume labour market segmentation. However, it is also of interest in its own right because empirical evidence suggests that in some developing economies labour markets may be largely integrated (see, e.g., El Badaoui et al. 2008 on South Africa and for general discussion of the empirical literature). In the second version we assume that segmentation is the result of a minimum wage, with which there is full compliance in formal employment. The simplicity of our diagrammatic formulation is thus bought at the cost of this limitation of the model. In practice, however, the wage floor in formal work might instead be the result of union bargaining or efficiency wage considerations, and there may be limited compliance with a minimum wage. In the concluding section we briefly discuss the potential for generalizing the model to allow for these factors.

For the benchmark model, we begin by characterizing the supply function of an agent to the three activities. Two cases are developed (depending on parameter values) that may be interpreted as corresponding to different underlying macroeconomic conditions, and the implications for labour market transitions that may occur as agents acquire greater skills are discussed. The model also generates a demand for wage labour by those agents who choose entrepreneurship. Given the joint distribution of $y$ and $z$ across individuals and a flexible wage rate, we characterize the labour market equilibrium and examine its comparative statics. We depict this equilibrium in a diagram which we later adapt to the second version of the model.

In practice, informality is generally associated with smaller size (Perry et al., 2007). This is because formal regulations may only apply to larger firms, and, insofar as they apply to all firms, informal firms may eschew larger size to avoid detection. ${ }^{5}$ In the second version of the model we therefore assume that the minimum wage rate applies only for firms above

2 Galiani and Weinschelbaum (2012) analyse both sides of the market, but their focus, in particular their concern with the effects of social programs, is different from ours.

3 In the absence of functioning systems of unemployment insurance and protection from job loss, open unemployment is 'rarely an option' for workers in developing economies (Ghosh, 2012).

4 This simplifying assumption is common in the informality literature. Its justification is that across the population we may expect differences in the ability to perform wage work to be relatively small, compared to ability in self-employment and entrepreneurship.

5 See Ahsan and Pages (2007) on India, and Almeida and Carneiro (2009) on Brazil. 
a certain size, with such firms being regarded as formal, and smaller firms as informal. For this case we show that informal and formal wage employment can coexist with voluntary and involuntary self-employment. If an agent who is rationed out of a formal wage job chooses self-employment, this is involuntary in the sense that it is not the agent's first choice-though it is voluntary in the sense that it is chosen freely from the remaining options. Involuntary entrepreneurship may also obtain, that is, agents who are rationed out of formal wage employment may choose, according to their second preference, to run a firm and employ others. ${ }^{6}$ Our analysis is not restricted to any particular rationing scheme to allocate formal jobs between the subset of agents who would like to take them. We note, however, that a potential inefficiency exists (in addition to the distortion caused by the minimum wage rate): agents who are lucky enough to gain formal jobs may actually have a comparative advantage in self-employment. In equilibrium this has an adverse effect on output by both informal and formal firms.

We end this section by considering briefly the transitions of workers between different labour market states. The empirical literature on Latin America indicates that young people tend to get informal jobs when they leave school, and these jobs are often used as a stepping stone to acquire skills. Formal employment may later be obtained, but for many the ultimate destination is voluntary self-employment (Perry et al., 2007; Bosch and Maloney, 2010; Cunningham and Salvagno, 2011). Although our model is not dynamic, it is found to be consistent with these observations.

To illustrate the model we explore an example calibrated so that it generates values that correspond broadly to Latin American data. This generates some implications for policy, albeit tentative ones given the stylized nature of the model. First, to diminish informality, a cut in the cost of formality may be more effective than an increase in the cost of informality. Second, it is more effective to provide education and training that improves the ability to produce and sell, rather than managerial skills. Third, policy changes that might have been expected to favour entrepreneurship may reduce the total number of entrepreneurs, whilst increasing (formal) employment and output by the relatively able ones.

Following the lead of Rauch (1991), many contributions to the informality literature, including Fortin et al. (1997), Amaral and Quintin (2006), Fiess et al. (2010), and de Paula and Scheinkman (2011), assume agents differ with respect to a single ability parameter. ${ }^{7}$ Antunes and Cavalcanti (2007) also include 'bequests' as a second dimension by which agents are characterized, and Galiani and Weinschelbaum (2012) incorporate into their analysis secondary workers (from the same household as the head), showing that these workers are likely to choose informal work. Although these analyses lay bare various

6 A related phenomonen in developed economies is the worker who is made redundant and then uses his or her redundancy payment or savings to set up a business.

7 Rauch's formulation incorporates informality into the framework developed by Lucas (1978). Jovanovic (1994) generalizes Lucas's approach in a different direction, including heterogeneity of both labour and management skills, but he is not concerned with informality (see also Poschke, 2013). A variation of the approach in the present article is formulated by Bennett et al. (2012), with individuals characterized in terms of both ability and risk aversion. It is found, for example, that the allocation of workers between informal and formal employment depends on the source of the risk involved in informal work (opportunistic non-payment by the employer or detection and penalties imposed by the authorities). 
important issues underlying informality in practice, they do not allow for the simultaneous existence of informal wage labour and informal self-employment. Gollin (2008) is an exception, developing a dynamic equilibrium model of capital accumulation in which an agent's time is split between self-employment and working as a wage employee. However, none of these contributions allow for the simultaneous existence of voluntary and involuntary informality.

Recently, a separate branch of the literature has grown, which develops searchand-matching models of informality. In this framework additional labour market states can be added at the cost of some complexity. In particular, in the formulation by Albrecht et al. (2009) all choices are voluntary, and a worker can be in one of four states: unemployment, informal self-employment, or formal wage employment either as a new hire (an outsider) or as an insider with a higher wage. Ability is one-dimensional, and it is assumed only to affect an agent's productivity in a formal sector job. A simulation gives insight into how workers respond to informal or formal job offers according to their ability and into the effects of different tax policies. A variation on this approach, with four labour market states (unemployment, self-employment, formal wage employment, and informal wage employment) is formulated by Margolis et al. (2012) as the basis for empirical analysis of the Malaysian labour market.

Section 2 formulates the benchmark version of the model, with a market-clearing wage rate. Section 3 introduces labour market segmentation, and Section 4 applies the model in the Latin American context, examining the policy conclusions. Section 5 concludes. Proofs are given in the Appendix.

\section{The benchmark model}

Consider a large population $P$ of agents, each of which is characterized in terms of two skills, $Y$ and $Z$. $Y$ may be thought of as the ability to produce and sell, and $Z$ as managerial skill. An agent's levels of $Y$ and $Z$ are distributed on the non-negative intervals $y \in[\underline{y}, \bar{y}]$ and $z \in[\underline{z}, \bar{z}]$, respectively. Skills are distributed across $P$ according to $f(y, z)$. Throughout, for simplicity, we assume that $f(\cdot)$ is continuous and positive for all $y$ and $z$.

Any agent may have one of three occupations: wage employment, self-employment, or entrepreneurship. We assume a self-employed person does not employ others-rather, any employment of others qualifies the person to be categorized as an entrepreneur. ${ }^{8}$ Regardless of an agent's $(y, z)$ characteristics, he or she has the same ability to do wage work as any other person. However, for self-employment and entrepreneurship, ability matters. If an agent with characteristics $(y, z)$ is self-employed, he or she produces the quantity $y$; that is, for self-employment 'the ability to produce and sell' matters, but 'managerial skills' do not. ${ }^{9}$ If, alternatively, he or she is an entrepreneur, the relevant measure of skill is

8 This assumption is consistent with the definition Lazear (2005) gives of an entrepreneur as being conceptually distinct from a self-employed person.

9 In practice self-employment covers a wide range of activity. Self-employed production with low $y$ may be, for example, construction work or street vending, whereas that with high $y$ may be, for example, professional work. A similar comment applies to entrepreneurial output. 
$\min (y, z) \equiv A$; that is, a balance of both types of skill matters. ${ }^{10}$ Such a person runs a firm for which the production function is

$$
x=A l^{\alpha}, \alpha \in(0,1)
$$

where $x$ is output and $l$ is the number of people the firm employs. Our specifications of production are chosen to keep the analysis simple. The same qualitative results would be obtained without the Leontief specification of $A$, provided the two types of skill are sufficiently weak substitutes; and with some concavity of the production function for the self-employed.

Let $q$ and $p$ be the prices for the output of the self-employed and entrepreneurial firms, respectively, and let $w$ be the money wage rate. An entrepreneur's profit is therefore $p x-$ $w l$, which, given eq. (1), is maximized at $l=\hat{l}(A)$, where

$$
\hat{l}(A)=\left(\frac{A p \alpha}{w}\right)^{\frac{1}{1-\alpha}}
$$

We assume that both self-employment and entrepreneurship give an agent a non-pecuniary benefit $v$, which may be thought of as the desire for independence. ${ }^{11}$ Thus, letting UW, US, and $U E$ denote the utility from working, self-employment, and entrepreneurship, respectively, we have

$$
U W=w ; \quad U S=q y+v ; \quad U E=p A \hat{l}^{\alpha}-w \hat{l}+v
$$

We shall only consider cases in which $w>v$, which is necessary for wage employment to exist in equilibrium.

We partition $P$ into three sets, $W, S$, and $E$, according to whether an agent's first preference is for wage employment, self-employment, or entrepreneurship, respectively. ${ }^{12}$ Thus, the sets are defined by

$$
\begin{aligned}
& W: U W>\max (U E, U S) \\
& S: U S>\max (U W, U E) \\
& E: U E>\max (U W, U S)
\end{aligned}
$$

10 Since we are concerned with relatively small firms, the productive and sales skills of the entrepreneur will generally matter for a firm's success. De Mel et al. (2010) suggest that the case for a jack-of-all-trades characterization is stronger if the market for business services is thin, as typically obtains in developing economies. Bloom et al. (2013) report on recent field experiments in developing countries that show that some forms of basic business training and advice can have significant effects on performance in small enterprises.

11 Perry et al. (2007) stress the significance of this non-pecuniary benefit in Latin America and the Caribbean. An implication in our model is that in equilibrium, depending on ability, some agents could earn more in informal wage employment than from self-employment, whereas for others the reverse is true. This is consistent with the mixed empirical evidence on which of these types of earnings is the higher (see, e.g., Agénor, 2007). With minor amendments, our analysis would still apply if $v=0$ or even if $v<0$, in which case $v$ might be interpreted as the disutility of extra effort required from independent/entrepreneurial work.

12 Throughout, we simplify the exposition by only specifying strong preference. 

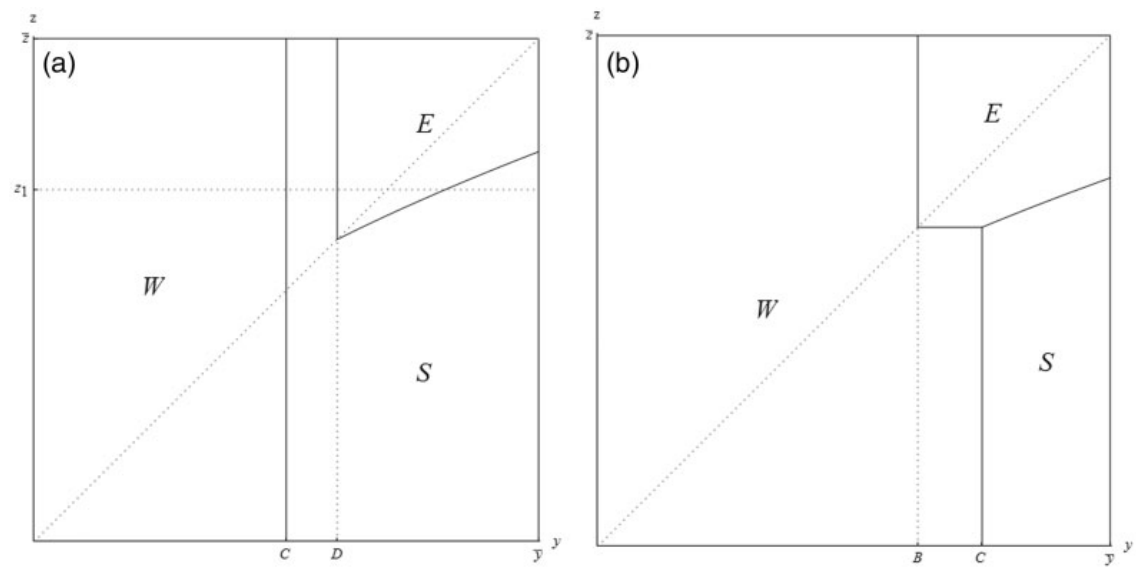

Fig. 1. Labour allocation for (a) $q / p>Q(w)$; and (b) $q / p<Q(w)$.

Using eqs (2) and (3), we can determine the borderline values of parameters underlying eq (4):

$$
\begin{gathered}
U W \gtrless U E \text { as } A \lessgtr B(w) \\
U W \gtrless U S \text { as } y \lessgtr C(w) \\
U E \gtrless U S \text { as } A \gtrless[D(w)]^{\alpha} y^{1-\alpha} \equiv \tilde{z}(y)
\end{gathered}
$$

where $B(w) \equiv(w / \alpha)^{\alpha}((w-v) /(1-\alpha))^{1-\alpha} / p ; C(w) \equiv(w-v) / q ; \quad$ and $\quad D(w) \equiv(w / p \alpha)$ $(q /(p(1-\alpha)))^{(1-\alpha) / \alpha}$. Note that $B(w)-C(w) \gtreqless 0$ as $q / p \gtreqless Q(w)$, where

$$
Q(w)=\alpha^{\alpha}(1-\alpha)^{1-\alpha}\left(\frac{w-v}{w}\right)^{\alpha}
$$

A relatively low $q / p$ might be interpreted as reflecting strong aggregate demand, being tilted towards the largely higher-quality output of entrepreneurial firms. Since $\alpha^{\alpha}(1-\alpha)^{1-\alpha} \in(1 / 2,1), Q(w) \in(0,1)$. Thus, if $q<p$ then either $q / p>Q(w)$ or $q / p<$ $Q(w)$; but if $q \geq p, q / p>Q(w)$.

Using eqs (5-8), Proposition 1 characterizes the allocation of agents to the three sets, $W$, $S$, and $E$ and Fig. 1 gives an intuitive illustration.

Proposition 1 Consider agent $i_{\mathrm{yz}}$ with characteristics $(y, z)$. (i) for $q / p>Q(w), i_{y z} \in W$ if $y<C(w) ; i_{y z} \in S$ if either $y \in(C(w), D(w))$ or both $y>D(w)$ and $z<\tilde{z}(y)$; and $i_{y z} \in E$ otherwise. (ii) for $q / p<Q(w), i_{y z} \in W$ if either $y<B$, or both $y \in(B(w), C(w))$ and $z<B$ $(w) ; i_{y z} \in S$ if $y>C(w)$ and $z<\tilde{z}(y)$; and $i_{y z} \in E$ otherwise.

In Fig. 1(a) $q / p>Q(w)$, and in Fig. 1 (b) $q / p<Q(w)$. Thus, for given $w$, in Fig. 1(a) self-employment is relatively more attractive, compared to entrepreneurship, than in Fig. 1(b). For simplicity, it is assumed in these figures that $\bar{y}=\bar{z}$ and $y=\underline{z}=0$. Consider Fig. 1(a), in which $q / p>Q(w)$. For individuals with $y<C(w)$ self-employment and entrepreneurship both offer relatively low rewards and so wage employment is preferred. If $y>C(w)$ either self-employment or entrepreneurship is preferred. For $C(w)<y<D(w)$ 
self-employment is preferred, but when $y>D(w)$, entrepreneurship is preferred if $z$ is large enough, with the critical value of $z$ increasing in $y{ }^{13}$

The figures may be interpreted in terms of an agent's transition between labour market states as skills are acquired. Consider, for example, an agent with skill $z=z_{1}$ in Fig. 1(a). Starting from a low level, the acquisition of greater skill $y$ enables a transition from $W$ to $S$, and then from $S$ to $E$; but the acquisition of sufficiently high skill $y$ enables a transition back to $S$. Thus, for some agents, even for changes in $y$ alone, the transition between labour market states may be non-monotonic. ${ }^{14}$ Figure $1(\mathrm{~b})$ is significantly different than Fig. 1(a) in that as $y$ rises, an agent may switch directly from $W$ to $E$, with no intermediate stage $S$. An implication is that, for increases in $y$ (or $z$ ) alone, monotonicity obtains, though, as in Fig. 1(a), some agents belong to $S$ at the highest values of $y$ even though at lower $y$ they would belong to $E$.

Remark 1 The mobility implications of education and training that affect individuals' ability $\mathrm{Y}$ can depend on macroeconomic factors $(p$ and $q$ ) as well as individual-specific ones ( $Z$ here).

In Fig. 1(a), where $q / p$ is low (strong aggregate demand) transitions may occur straight from $W$ to $E$, however small the increase in $Y$. But in Fig. 1(b), where $q / p$ is high (weak aggregate demand) only a relatively large addition to skill $Y$ would enable direct transition from $W$ to $E$; in the absence of such large additions to skill, self-employment may play an important transitional role.

Aggregating over $P$, we obtain the supplies of labour to the three activities. We denote the total supplies to wage employment, self-employment, and entrepreneurship by $L^{s}, S E^{s}$, and $E^{s}$, respectively. For each entrepreneur the demand for labour is given by $\hat{l}(A)$ in eq. (2) and thus we obtain the total demand for labour, $L^{d}$.

Lemma 1 The comparative statics of the supply and demand for wage labour are as follows:

$$
\begin{aligned}
& L_{p}^{d}>0 ; L_{q}^{d}<0 ; L_{w}^{d}<0 ; L_{q}^{s}<0 ; L_{w}^{s}>0 ; L_{v}^{s}<0 \\
& \quad L_{v}^{d}\left\{\begin{array}{lll}
=0 & \text { for } q / p>Q(w) \\
>0 & \text { for } q / p<Q(w)
\end{array} ; L_{p}^{s} \begin{cases}=0 & \text { for } q / p>Q(w) \\
<0 & \text { for } q / p<Q(w)\end{cases} \right.
\end{aligned}
$$

The demand for wage labour is increasing in the price of the firms' output and decreasing in the money wage. It is decreasing in the price paid for the output of the self-employed because a higher price for this output makes entrepreneurship relatively less attractive. A greater benefit, $v$, from independence makes entrepreneurship (and self-employment) more attractive relative to wage employment. However, this is only associated with more agents choosing entrepreneurship if there are agents on the margin of choice between entrepreneurship and wage employment (Fig. 1(b)).

13 If there were some limited substitutability of the two skills in the entrepreneurial production function, there would be no straight boundaries between $E$ and the other sets, but the properties of the figure would be unaffected.

14 If there is incremental acquisition of both skills $y$ and $z$, and this occurs sequentially over time, then repeated switches between $E$ and $S$ are also possible. 
The supply of wage labour is increasing in the money wage rate, and decreasing in the price of self-employed output and benefit from independence. If the output price $p$ is higher then, again, provided there are agents on the margin of choice between entrepreneurship and wage employment (Fig. 1(b)), wage employment becomes less attractive relative to entrepreneurship for these agents, and so the supply of wage labour is lower.

We can now specify sufficient conditions for equilibrium in the labour market, including the coexistence of wage employment and self employment. We denote the lowest and highest levels of $A$ in $P$ by $\underline{A}$ and $\bar{A}$, respectively, and we define $\underline{w}$ and $\bar{w}$ as

$$
U E(\underline{A}, \underline{w})=U W(\underline{w}) ; \quad U E(\bar{A}, \bar{w})=U W(\bar{w})
$$

Thus, $\underline{w}$ is the level of the wage $w$ at which an agent with $A=\underline{A}$ would be indifferent between being an entrepreneur and a worker, and $\bar{w}$ is defined similarly for $A=\bar{A}$.

Proposition 2 If $U E(\underline{A}, \underline{w})<U S(\underline{y})<U W(\bar{w})<U S(\bar{y})<U E(\bar{A}, \underline{w})$ then there exists a wage $w^{*} \in(\underline{w}, \bar{w})$ such that $L^{d}\left(w^{*}\right)=L^{s}\left(w^{*}\right)$ and the sets $E, S, W$ are non-empty.

Depending on whether the market-clearing wage rate $w^{*}$ is such that $q / p>Q\left(w^{*}\right)$ or $q / p<Q\left(w^{*}\right)$, Fig. $1(\mathrm{a})$ or $1(\mathrm{~b})$, respectively, can be interpreted as representing this equilibrium.

Lemma 2 In equilibrium $\left(w=w^{*}\right), d w / d p>0, d w / d q \gtrless 0$, and $d w / d v>0$; and total wage employment $L$ satisfies

$$
\begin{gathered}
\frac{d L}{d p}>0\left\{\begin{array}{l}
\text { if } q / p>Q\left(w^{*}\right), \\
\text { if } q / p<Q\left(w^{*}\right) \text { and } L_{p}^{d} L_{w}^{s}-L_{w}^{d} L_{p}^{s}>0
\end{array}\right. \\
d L / d q<0 ; \\
\frac{d L}{d v} \begin{cases}<0 & \text { if } q / p>Q\left(w^{*}\right) \\
\gtrless 0 & \text { if } q / p<Q\left(w^{*}\right)\end{cases}
\end{gathered}
$$

If the price $p$ of the entrepreneurial output is higher then $L^{d}$ is greater, as is $w^{*}$. Set $W$ is therefore larger, subject, when $q / p<Q\left(w^{*}\right)$, to a stability condition. If the output price $q$ for the self-employed is higher, the greater attractiveness of self-employment is associated with lower supply of and lower demand for wage labour, the latter effect arising because the supply of entrepreneurship is smaller. Thus, $W$ is smaller, but the net effect on $w^{*}$ may be of either sign. A greater desire for independence $v$ stimulates both self-employment (reducing the supply of wage labour) and entrepreneurship (increasing the demand for wage labour). The latter effect implies a greater demand for wage labour, but as the supply of wage labour is smaller we can only sign the effect on $W$ when $q / p>Q\left(w^{*}\right)$.

\section{Labour market segmentation}

We now examine the equilibrium that obtains when the wage rate $w$ is fixed by law, at $w_{f}$, above the market-clearing level $w^{*}$. As first specified by Rauch (1991), we assume that only firms above a certain threshold employment level $l=l_{0}$ pay the minimum wage $w_{f}$, whereas firms with $l \leq l_{0}$ pay the market-clearing wage $w=w_{i}$. The former firms are denoted 'formal' and the latter 'informal'. In Rauch's model (in which skill is onedimensional) there is a critical entrepreneurial skill level above which formality is chosen, 
with informality being chosen otherwise. In our model there is a critical level of $A, A=\tilde{A}$, that plays a similar role. This is the level of $A$ at which the entrepreneur achieves the same utility from operating informally at the maximum employment level $l_{0}$ as from operating formally at the higher, profit-maximizing employment level $\hat{l}(A)$, that is,

$$
U E\left(\tilde{A}, w_{i}, l_{0}\right)=U E\left(\tilde{A}, w_{f}, \hat{l}(\tilde{A})\right)
$$

Of agents choosing entrepreneurship, those with $A>\tilde{A}$ choose formality. As in Rauch's model there is a gap in the size distribution of firms at $A=\tilde{A}$.

With this revised model, the utility from self-employment is the same as in eq. (3), but we now distinguish the respective utilities, $U_{f}$ and $U_{i}$ from formal and informal wage work:

$$
U S=q y+v ; \quad U W_{f}=w_{f} ; \quad U W_{i}=w_{i}
$$

The utilities from formal and informal entrepreneurship are denoted by $U E_{f}$ and $U E_{i}$, where

$$
U E_{j}=p A \hat{l}_{j}^{\alpha}-w_{j} \hat{l}_{j}+v, j=f, i
$$

For an informal entrepreneur $(A \leq \tilde{A})$, if there were no constraint on informal employment we would have $l_{i}=\hat{l}_{i}(A)=\left(A p \alpha / w_{i}\right)^{1 /(1-\alpha)}$. So the constraint $l \leq l_{0}$ binds exactly if $\left(A p \alpha / w_{i}\right)^{1 /(1-\alpha)}=l_{0}$; that is, if $A=w_{i} l_{0}^{1-\alpha} / p \alpha \equiv A_{0}$. Thus, for firms operating informally,

$$
l_{i}=\left\{\begin{array}{lll}
\hat{l}_{i}(A) & \text { if } & A_{0}>A ; \\
l_{0} & \text { if } & \tilde{A} \geq A \geq A_{0}
\end{array}\right.
$$

and for firms operating formally

$$
l_{f}=\hat{l}_{f}=\left(\frac{A p \alpha}{w_{f}}\right)^{\frac{1}{1-\alpha}}
$$

The population $P$ can be partitioned into four sets according to their first preferences in the labour market. ${ }^{15}$ In the Appendix we specify the inequalities parallel to eqs (5-8) that underlie these first preferences (as well as those underlying second preferences). Our notation will be to write in parentheses $f$ for formal and $i$ for informal, and then add a subscript $V$ for voluntary and $I$ for involuntary if a further distinction is necessary. Thus, all agents belong to one of the following sets.

i. Formal entrepreneurship, denoted $E(f)$; defined by $U E_{f}>\max \left(U E_{i}, U S, U W_{f}\right)$.

ii. Voluntary informal entrepreneurship, denoted $E_{V}(i)$; defined by $U E_{i}>\max$ $\left(U E_{f}, U S, U W_{f}\right)$.

iii. Voluntary self-employment, denoted $S_{V ;}$ defined by $U S>\max \left(U E_{f}, U E_{i}, U W_{f}\right)$.

iv. Formal employment, denoted $W(f)$; defined by $U W_{f}>\max \left(U E_{f}, U E_{i}, U S\right)$.

Set $W(f)$ can be partitioned into those agents who obtain a formal job (set $W(f)^{+}$) and those who do not (set $\left.W(f)^{-}\right)$. Members of set $W(f)^{-}$attain their second preferences,

15 For each agent, the first preference is 'voluntary', but we only use this term in naming a set if the distinction will be necessary where we specify 'involuntary' sets (for which a similar comment applies). 
that is, they allocate their labour 'involuntarily'. Each belongs to one of the following sets. $^{16}$

i. Involuntary informal entrepreneurs, denoted $E_{I}(i)$; defined by $U E_{i}>\max \left(U S, U W_{i}\right)$.

ii. Involuntary self-employed, denoted $S_{I}$; defined by $U S>\max \left(U E_{i}, U W_{i}\right)$.

iii. Informal employees, denoted $W(i)$; defined by $U W_{i}>\max \left(U E_{i}, U S\right)$.

Proposition 3 Suppose firms may be formal, with $l>l_{0}$ and paying wage $w_{f}$, where $w_{f}>w^{*}$, or informal, with $l \leq l_{0}$ and paying the market clearing wage $w_{i}$. Then the sets $E(f), E_{V}(i), S_{V}, W(f)^{+}, E_{I}(i), S_{I}$, and $W(i)$ may, simultaneously, all be non-empty in equilibrium.

We prove the proposition by giving an example in which, indeed, the sets $E(f), E_{V}(i), S_{V}$, $W(f)^{+}, E_{I}(i), S_{I}$, and $W(i)$ are, simultaneously non-empty in equilibrium. We delay giving this example until Section 5, however, where we relate it to Latin American data, because we wish to consider this example in its own right. The sets listed in the proposition are not necessarily non-empty, and degenerate equilibria may easily be formulated (e.g., if $q / p$ were sufficiently high all agents would belong to set $S_{V}$ ). But we focus on cases in which all the sets (except possibly $E_{I}(i)$ ) are non-empty because these correspond to the labour markets observed in practice.

Proposition 3 is illustrated in Fig. 2, which is a development of Fig. 1, and can be interpreted as representing the equilibrium with endogenous adjustment of $w_{i}$. As previously, the cases shown correspond to different ranges of $q / p$ relative to $Q$, but whereas in Fig. $1 Q$ was a function of the single wage rate $w^{*}$, now there are two wage rates, $w_{f}$ and $w_{i}$ in the model. The relevant formulation is $Q\left(w_{i}, w_{j}\right)$ with $j=f$, $i$, where the first argument is the unit cost of labour to the entrepreneur and the second is the wage earned in activity $j .{ }^{17}$ This is derived in the Appendix, along with the borderline parameter values $B(\cdot, \cdot), C(\cdot)$, and $D(\cdot)$ shown in Fig. 2. Figure 2(a) illustrates the case in which $q / p>Q\left(w_{i}, w_{f}\right)>$ $Q\left(w_{i}, w_{i}\right)$, which corresponds to the case shown in Fig. 1(a); in Fig. 2(b) $Q\left(w_{i}, w_{f}\right)>$ $q / p>Q\left(w_{i}, w_{i}\right)$, which is essentially a hybrid of the Fig. 1(a) and $1(\mathrm{~b})$ cases; and in Fig. 2(c) $Q\left(w_{i}, w_{f}\right)>Q\left(w_{i}, w_{i}\right)>q / p$, which corresponds to Fig. 1(b). Each of the panels can be explained in three steps. ${ }^{18}$

First, using eqs (1-7) with $w=w_{f}$ and eq. (10), we determine the $(y, z)$ characteristics of the members of the 'first-preference' sets $E(f), E_{V}(i), S_{V}$, and $W(f)$. The first three of these sets are shown unshaded, whereas set $W(f)$ is shown by the entire shaded area in each panel.

Second, because the rationing scheme has not been specified, note that membership of set $W(f)^{+}$may come from anywhere in the shaded area (set $\left.W(f)\right)$ in each panel.

Third, disregarding temporarily the allocation of agents to set $W(f)^{+}$, we treat the shaded area in the same way as we did the whole of $(y, z)$ space in Fig. $1(\mathrm{a})$ and $1(\mathrm{~b})$. Thus, for the

16 No $(y, z)$ combinations exist for which both (i) formal employment is first preference and (ii) formal entrepreneurship second preference, that is, involuntary formal entrepreneurship is not feasible.

17 In Fig. 1(a) and 1 (b) $Q\left(w^{*}\right)$ is the critical value of $q / p$ determining whether the borderline value of $y$ (and of $z$ for entrepreneurship) at which $U W=U E$ is greater or less than that at which $U W=U S$. Now two different values of $Q$ come into play, depending on whether an employed agent earns $w_{f}$ or $w_{i}$

18 If $w_{f}$ is not significantly above $w^{*}$ the horizontal boundary of the set $E(f)$ will meet the upwardssloping boundary of set $E_{\backslash}(i)$ and terminate there. 

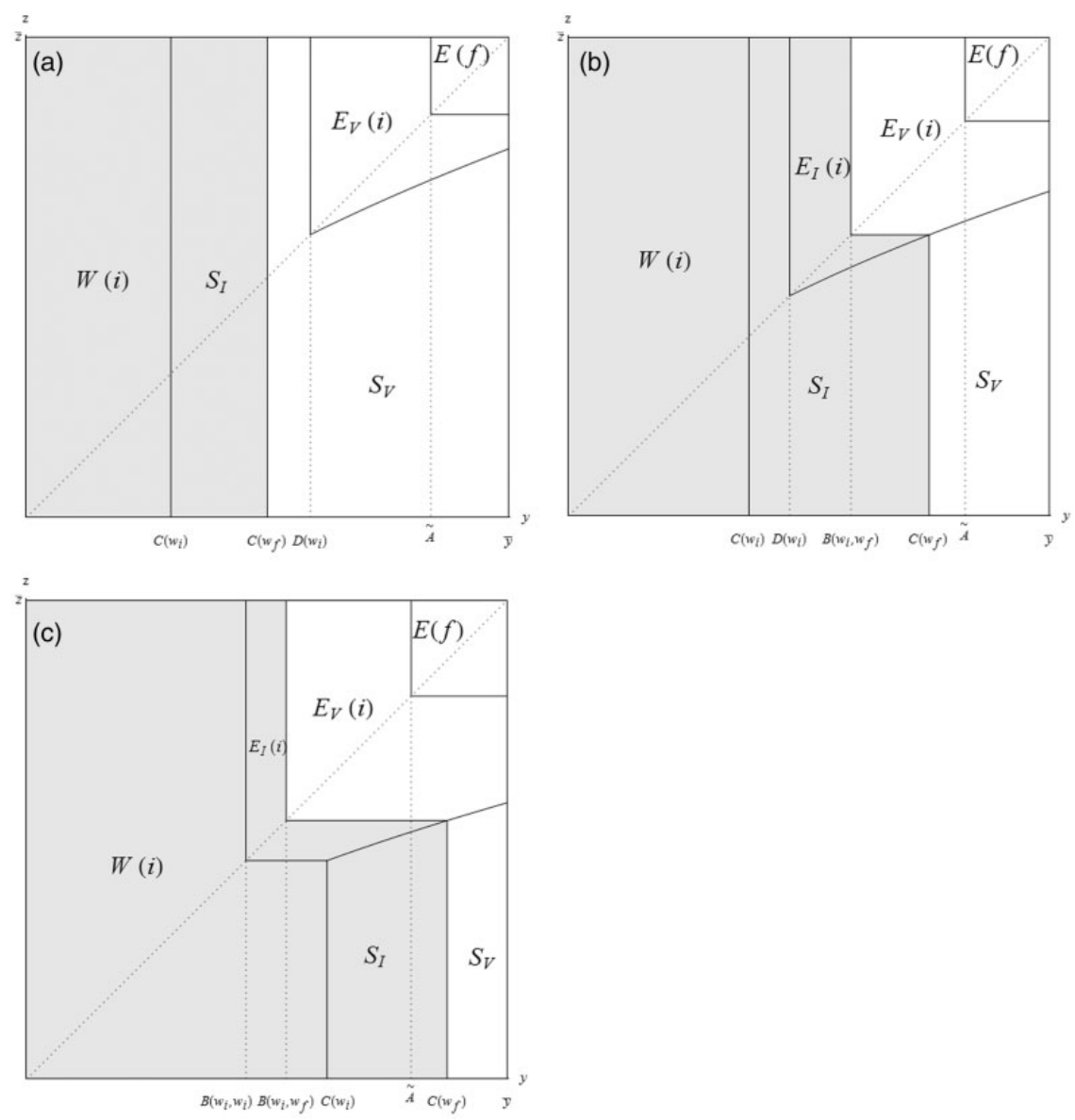

Fig. 2. Labour allocation for (a) $q / p>Q\left(w_{i}, w_{f}\right)>Q\left(w_{i}, w_{i}\right)$; (b) $Q\left(w_{i}, w_{f}\right)>q / p>Q\left(w_{i}, w_{i}\right)$; and (c) $Q\left(w_{i}, w_{f}\right)>Q\left(w_{i}, w_{i}\right)>q / p$. Shaded area denotes the set $W(f)$.

agents concerned, we show the preference amongst the three options of entrepreneurship, self-employment, and informal wage employment, given that all three options are involuntary in the sense that these agents would prefer formal wage employment. Hence we determine the 'second-preference' sets $E_{I}(i), S_{I}$, and $W(i)$, with the proviso that a selection of agents with $(y, z)$ characteristics consonant with these sets, belong instead to set $W(f)^{+}$.

For a given $(y, z)$ distribution, we assume that $w_{i}$ adjusts endogenously such that informal wage labour supply (from set $W(i)$ ) equals informal wage labour demand (from set $\left.E_{V}(i) \cup E_{I}(i)\right)$. The other allocations are determined simultaneously. It can be seen that relatively highly skilled agents with a balanced skill set become formal entrepreneurs, whilst those not quite so highly skilled and/or with not quite so balanced skill sets become voluntary informal entrepreneurs. Agents with a high $y$ but sufficiently low $z$ become voluntarily self-employed.

In Fig. 2(a), the return to self-employment is relatively high $\left(q / p>Q\left(w_{i}, w_{f}\right)>\right.$ $\left.Q\left(w_{i}, w_{i}\right)\right)$. Consequently, there is no involuntary informal entrepreneurship, involuntary self-employment being preferred instead. However, the return to self-employment is not so 
high in Fig. 2(b) and 2(c), and so some involuntary entrepreneurship obtains, with the agents concerned having lower values of $A=\min (y, z)$ than voluntary entrepreneurs. Roughly speaking, involuntary informal entrepreneurs have high values of $z$, but intermediate values of $y$, although a member of set $S_{I}$ may have more of both skills than a member of set $E_{I}(i)$.

Remark 2 The rationing scheme for formal wage employment may create an (additional) inefficiency, with output being forgone from self-employment, and both informal and formal entrepreneurial firms.

Unless the formal wage employees are those with the smallest $y$ endowments in the shaded area in each panel of Fig. 2, some output by the involuntarily self-employed is forgone. Also, in Fig. 2(b) and 2(c), insofar as some agents from the shaded area associated with $E_{I}(i)$ gain formal employment, there is a negative effect on informal wage labour demand and the supply of informal output. This negatively affects the informal wage rate $w_{i}$, causing substitution out of formal wage employment and output.

In each panel of Fig. 2 an agent with low skills will—unless they manage to obtain formal wage employment-begin in set $W(i)$. As they acquire skills, they will move north-east in the figure, perhaps shifting into set $S_{I}$. Nonetheless, there is a possible non-monotonic transition in the sense that if an agent moves from (involuntary) self-employment into a formal wage job, they may then go back to (voluntary) self-employment if their skills develop sufficiently. ${ }^{19}$ Our model is thus broadly consistent with the empirical evidence on Latin American transitions. However, there are significant differences between the panels in Fig. 2 in terms of the possible transitions from informal wage work to entrepreneurship. If skills are acquired incrementally, in Fig. 2(a) an agent will move through intermediate stages of involuntary and voluntary self-employment. In Fig. 2(b), where $q / p$ is not as great as in Fig. 2(a), the only intermediate stage is involuntary self-employment, whilst in Fig. 2(c), where $q / p$ is lower still, there is no intervening stage of self-employment.

\section{An application to Latin American data}

To illustrate the model we calibrate it using Latin American data. We assume a joint lognormal distribution of skills $Y$ and $Z$ :

$$
f(y, z)=\frac{e^{-k / 2 \sigma^{2}}}{2 \pi \sigma^{2} y z}
$$

where $k \equiv(\log y)^{2}+(\log z)^{2}$ and $\sigma$ is a constant. We fix $\alpha=0.5$, for there appears no compelling justification for any particular calibration of this parameter. We set $l_{0}=5$ on the basis of the survey of informality by Oviedo et al. (2009), who note that informal firms 'mostly' have five or fewer employees.

The remaining parameters $-p, q, v, w_{f}, \sigma-$ are calibrated such that our model matches some recent statistics for various countries in Latin America and the Caribbean reported by Perry et al. (2007). These are that the proportions of paid private non-domestic employment in urban areas (excluding entrepreneurs) are $37 \%$ formal waged, $28 \%$ informal waged, and $34 \%$ and self-employed, whilst the informal wage is around $59 \%$ of

19 As in the benchmark model, if $q / p$ is sufficiently large, there can be non-monotonic transitions from self-employment to entrepreneurship and back again. 
Table 1. An example for Latin America

\begin{tabular}{|c|c|c|c|c|c|c|c|}
\hline \multirow[t]{2}{*}{ Baseline $(\%$ of $P$ ) } & \multicolumn{7}{|c|}{ Parameter change } \\
\hline & $q$ & $p$ & $v$ & $w_{f}$ & $l_{0}$ & Y & Z \\
\hline$|E(f)|=0.63$ & 0 & + & + & - & - & + & + \\
\hline$\left|E_{V}(i)\right|=6.86$ & - & - & - & + & - & - & + \\
\hline$\left|E_{I}(i)\right|=0.09$ & - & - & - & + & - & - & - \\
\hline$\left|E(f) \cup E_{V}(i) \cup E_{I}(i)\right|$ & - & + & - & + & - & - & + \\
\hline$\left|S_{V}\right|=23.35$ & + & - & + & - & + & + & - \\
\hline$\left|S_{I}\right|=7.77$ & + & - & + & + & - & - & - \\
\hline$\left|S_{V} \cup S_{I}\right|$ & + & - & + & + & - & + & - \\
\hline$\left|W(f)^{+}\right|=35.40$ & 0 & + & + & - & - & + & + \\
\hline$|W(i)|=25.99$ & - & - & - & + & + & - & + \\
\hline$\left|W(f)^{+} \cup W(i)\right|$ & - & + & - & - & + & - & + \\
\hline$w_{i} / w_{f}=0.5807$ & - & + & + & - & + & + & + \\
\hline
\end{tabular}

Notes: $q=0.55, p=0.9, \alpha=0.5, v=0.1, w_{f}=1.1, l_{0}=5, \sigma=1.63$.

the formal wage. ${ }^{20}$ As we have one additional parameter to calibrate relative to the number of statistics, we impose one further restriction to identify a unique calibration, that the benefit from independence $v$ is $10 \%$ of the minimum wage $w_{f}{ }^{21}$

We search numerically for the parameter values that obtain in our model under the assumption that the rationing scheme for allocating agents in set $W(f)$ to set $W(f)^{+}$is random. Because we use a dense lattice to approximate the infinite population of agents assumed in the model, a small degree of coarseness prevents us from matching these statistics with absolute precision. However, after adjusting the first three statistics above to account for entrepreneurs, the reported estimates (shown under Table 1) match to within 1 percentage point. For these calibrated parameter values, the price of entrepreneurial output $p$ is around two-thirds higher than the price of self-employed output $q$. Table 1 shows the comparative statics of various parameter changes. The first five columns show the signs for small increases in the value of each of the parameters listed, and last two columns give the effects of positive incremental shifts in the distributions shown.

The comparative statics signs shown in the table can be understood intuitively for any parameter by considering the effect on first preferences and then on second preferences. Consider, for example, an increase in the self-employed price $q$. Because there are no agents on the borderline of choice between formal entrepreneurship and self-employment, this has no effect on set $E(f)$, and therefore none on $W(f)^{+}$. However, it causes a switch in first preferences away from formal employment and informal entrepreneurship towards selfemployment, and so set $E_{V}(i)$ becomes smaller and $S_{V}$ larger. The higher value of $q$ also

20 The proportions of employment are cross-country averages derived from Table 2.1 of Perry et al. (2007), which uses the social protection/legal definition of informality. There is wide variation across countries and types of worker in the formal-informal wage gap. The figure of $59 \%$ in the text relates to an average-earnings job in Argentina.

21 This value is consistent with recent research reviewed by Carter (2010)—albeit for developed economies-which argues that the compensating differential from self-employment is substantially smaller than the widely cited estimate of Hamilton (2000) of $35 \%$ of equivalent employment income. 
causes a shift towards self-employment as a second preference, and so set $S_{I}$ becomes larger, but $W(i)$ and $E_{I}(i)$ smaller. Although the supply of informal labour falls, the decrease in the demand dominates and $w_{i}$ falls. Overall, there are more self-employed and fewer entrepreneurs and wage workers. Similar explanations can be given for other parameter changes, but for brevity we focus on some potential policy tools.

First, consider changes in parameters $w_{f}$ and $l_{0} . l_{0}$ can be regarded as a policy tool even if it is not fixed by government regulation; changes in the probability of detection of informality or in the penalties when caught would affect the informal employment level that entrepreneurs are willing to set. A lower $w_{f}$ is a reduced cost of formality, whereas a lower $l_{0}$, limiting informal firm size further can be interpreted as an increased cost of informality. We might expect each of these changes to result in less informality. Indeed, reducing $w_{f}$ does cause $E(f)$ and $W(f)^{+}$to become larger, whilst $E_{V}(i)$ and $W(i)$ become smaller. However, whilst a reduction in $l_{0}$ also causes $E(f)$ and $W(f)^{+}$to expand and $W(i)$ to contract, the effect on informal activity is not clear-cut, for it expands $E_{V}(i)$ and $E_{I}(i)$. Thus, in this example, if the aim is to reduce informality, a reduction in $w_{f}$ might be preferred. Nonetheless, although a reduction in the minimum wage rate is a shift towards the (static) first best, the reduction it causes in the number of informal entrepreneurs may also have an adverse longer-term effect if informal entrepreneurship provides a learning experience for some potential future formal entrepreneurs.

Second, the results are suggestive of the effects of different types of education/training. In Table 1 a general increase in skill $Z$ expands both $E(f)$ and $E_{V}(i)$, as well as $W(f)^{+}$and $W(i)$, whilst both $S_{V}$ and $S_{I}$ are diminished. However, a general increase in skill $Y$, with or without an associated increase in $Z$, diminishes $E_{V}(i)$ and $W(i)$, whilst a switch occurs into $S_{V}$ from $S_{I}$. Suppose that both general education and on-the-job training would increase the stock of $Y$, whereas specialist management training is required to increase the stock of $Z$. This suggests that, if the aim is to reduce informality then, because of the role played by voluntary self-employment, general education and on-the-job training is more effective.

\section{Concluding comments}

We construct a parsimonious model that captures some of the complexity that obtains in urban labour markets in developing economies. In the benchmark version the labour market is unsegmented and agents may be in one of three states-self-employment, wage employment, and entrepreneurship. The second version of the model adds labour market segmentation. In equilibrium, voluntary and involuntary self-employment, formal and informal wage employment, and formal and informal entrepreneurship (the latter possibly dividing into voluntary and involuntary components) may all coexist. We also develop a diagrammatic interpretation of the segmented and the unsegmented cases.

Our analysis suggests the importance of underlying macroeconomic conditions in determining the effects of education and training on transitions of individuals between labour market states, and that these transitions may be non-monotonic. The role of the rationing scheme by which workers are selected for formal jobs is also highlighted. As an illustration, a numerical example is developed that generates results that correspond closely to Latin American experience. In this example, if the government wishes to reduce informality, reduction of the costs of formality is generally more effective than increasing the costs of informality, whilst education and training that improves the ability of individuals to produce and sell is more effective than increasing managerial skills. 
These results are obtained from a highly stylized model, in particular from the assumption of a competitive labour market, the only imperfection being that a minimum wage must be paid by formal employers. However, we conjecture that some alternative assumptions could be accommodated into our framework relatively easily. For example, partial compliance by formal firms with the minimum wage law would shift the boundary between formal and informal entrepreneurship to the south-west in Fig. 2 (assuming that expected penalties for detection are not too large). The potential effects would include a substitution into formal from informal entrepreneurship and, as the informal wage would be driven up, there would also be a substitution out of informal entrepreneurship into voluntary and involuntary self-employment.

Similar effects would be obtained if trade unions were included in the model, with insiders and outsiders amongst formal-firm employees. However, a more radical overhaul of the analysis would be required to allow for decentralized bargaining between unions and employers, or for efficiency wages. For example, in a moral hazard or nutritional model it would have to be taken into account how worker productivity depends on wage rates. A more straightforward generalization that might be made would be to allow for heterogenous innate ability in wage work. Amongst other factors that might be included are free labour provided by the family and wealth and liquidity constraints that might hold back both self-employment and entrepreneurship.

\section{Acknowledgements}

We are grateful for helpful comments by Nancy Chau, Francis Teal, and two anonymous referees. We also thank participants at the IZA/World Bank Workshop on Institutions and Informal Employment in Emerging and Transition Economies, Bonn, 2011, and at a seminar at the CSAE, Oxford.

\section{References}

Agénor, P.-R. (2007) The analytics of segmented labour markets, in P.-R. Agénor, A. Izquierdo, and H.T. Jensen (eds) Adjustment Policies, Poverty, and Unemployment: The IMMPA Framework, Wiley-Blackwell, New York.

Ahsan, A. and Pages, C. (2007) Are all labor regulations equal? Assessing the effects of job security, labor dispute, and contract labor laws in India, World Bank Policy Research Working Paper No. 4259, World Bank, Washington, DC.

Albrecht, J., Navarro, L. and Vroman, S. (2009) The effects of labour market policies in an economy with an informal sector, Economic Journal, 119, 1105-29.

Almeida, R. and Carneiro, P. (2009) Enforcement of labor regulation and firm size, Journal of Comparative Economics, 37, 28-46.

Amaral, P.S. and Quintin, E. (2006) A competitive model of the informal sector, Journal of Monetary Economics, 53, 1541-53.

Antunes, A.R. and Cavalcanti, T. (2007) Start up costs, limited enforcement, and the hidden economy, European Economic Review, 51, 203-24.

Bennett, J., Gould, M. and Rablen, M.D. (2012) Risk attitudes and informal employment in a developing economy, IZA Journal of Labor and Development, 1,5.

Bloom, N., Eifert, B., Mahajan, A., McKenzie, D. and Roberts, J. (2013) Does management matter? Evidence from India, Quarterly Journal of Economics, 128, 1-51.

Bosch, M. and Maloney, W.F. (2010) Comparative analysis of labour market dynamics using Markov processes: an application to informality, Labour Economics, 17, 621-31. 
Carter, S. (2010) The rewards of entrepreneurship: exploring the incomes, wealth, and economic well-being of entrepreneurial households, Entrepreneurship Theory and Practice, 35, 39-55.

Cunningham, W. and Salvagno, J.B. (2011) Youth employment transitions in Latin America, World Bank Policy Research Working Paper No. 5521, World Bank, Washington, DC.

de Mel, S., McKenzie, D., and Woodruff, C. (2010) Who are the microenterprise owners? Evidence from Sri Lanka on Tokman versus de Soto, in J. Lerner and A. Schoar (eds) International Differences in Entrepreneurship, University of Chicago Press, Chicago.

de Paula, A. and Scheinkman, J. (2011) The informal sector: an equilibrium model and some empirical evidence from Brazil, Review of Income and Wealth, 57, S8-S26.

El Badaoui, E., Strobl, E. and Walsh, F. (2008) Is there an informal employment wage penalty? Evidence from South Africa, Economic Development and Cultural Change, 56, 683-710.

Fields, G.S. (2009) Segmented labor market models in developing countries, Chapter 18, in H. Kincaid and D. Ross (eds) The Oxford Handbook of Philosophy of Economics, Oxford University Press, New York.

Fiess, N., Fugazza, M. and Maloney, W. (2010) Informal self-employment and macroeconomic fluctuations, Journal of Development Economics, 91, 211-26.

Fortin, B., Marceau, N. and Savard, L. (1997) Taxation, wage controls and the informal sector, Journal of Public Economics, 66, 293-312.

Galiani, S. and Weinschelbaum, F. (2012) Modeling informality formally: households and firms, Economic Inquiry, 50, 821-38.

Ghosh, J. (2012) Global crisis and beyond: Sustainable growth trajectories for the developing world, International Labour Review, 149, 209-25.

Gollin, D. (2008) Nobody's business but my own: self-employment and small enterprise in economic development, Journal of Monetary Economics, 55, 219-33.

Hamilton, B.H. (2000) Does entrepreneurship pay? An empirical analysis of the returns to selfemployment, Journal of Political Economy, 108, 604-31.

Jovanovic, B. (1994) Firm formation with heterogeneous management and labor skills, Small Business Economics, 6, 185-91.

Lazear, E.P. (2005) Entrepreneurship, Journal of Labor Economics, 23, 649-80.

Lucas, R.E. (1978) On the size distribution of business firms, Bell Journal of Economics and Management Science, 9, 508-23.

Margolis, D.N., Navarro, L. and Robalino, D.A. (2012) Unemployment insurance, job search and informal employment, IZA Discussion Paper No. 6660, IZA, Bonn.

Oviedo, A.M., Thomas, M.R. and Karakurum-Özdemir, K. (2009) Economic informality: causes, costs, and policies—a literature survey, World Bank Working Paper No. 167, World Bank, Washington, DC.

Perry, G.E., Maloney, W.F., Arias, O.S., Fajnzylber, P., Mason, A.D. and Saavedra-Chanduvi, J. (2007) Informality: Exit and Exclusion, World Bank, Washington, DC.

Poschke, M. (2013) The decision to become an entrepreneur and the firm size distribution: a unifying framework for policy analysis, IZA Discussion Paper No. 7757, IZA, Bonn.

Rauch, J.E. (1991) Modelling the informal sector formally, Journal of Development Economics, $35,33-47$.

\section{Appendix}

Proposition 1 Consider first the conditions under which wage employment is preferred. If $q / p>Q(w)$ then $C<B$. Since $A \leq y$, we have that $y<C(w) \Rightarrow A \leq y<C(w)<B(w)$; that is, eq. (6) is sufficient for eq. (5) to be satisfied. If $q / p<Q(w)$ then $B(w)<C(w)$. To satisfy 
eqs (5) and (6), we need either $y<B(w)$ or $y \in(B(w), C(w))$ and $z<B(w)$ (since $A \leq z$, so that $z<B(w)$ is sufficient for $A<B(w))$.

Now consider the conditions under which self-employment is preferred. We have seen that $y>C(w) \Rightarrow U S>U W$, so now consider what is required for $U S>U E$. First, suppose $A=z$; then, from eq. (7), UE $>$ US if $A>[D(w)]^{\alpha} y^{1-\alpha} \equiv \tilde{z}(y)$. For this to be consistent with $A=z$ we require $y \geq \tilde{z}(y)$. Note that, for $y>0, \tilde{z}(y)$ has a unique fixed point, $\tilde{z}(D(w))=$ $D(w)$, and that $\tilde{z}^{\prime}(y)=(1-\alpha)[D(w)]^{\alpha} y^{-\alpha}>0$, so that $\tilde{z}^{\prime}(D(w))=1-\alpha<1$. Because also $\tilde{z}^{\prime \prime}(y)=-\alpha(1-\alpha)[D(w)]^{\alpha} y^{-\alpha-1}<0$, this implies that $y \gtrless D(w) \Leftrightarrow y \gtrless \tilde{z}(y)$. Hence, if $y>D(w)$, we have $U S>U E \Leftrightarrow z<\tilde{z}(y)$. Alternatively, suppose $A=y$. Then, from eq. (7) $y<D(w) \Rightarrow U S>U E$.

Hence $U S>U E$ if either (i) $y<D(w)$ or (ii) $y>D(w)$ and $z<\tilde{z}(y)$. Therefore US $>\max (U W, U E)$ when either (i) $y \in(\min (C(w), D(w)), D(w))$ or (ii) $y>\max$ $(C(w), D(w))$ and $z<\tilde{z}(y)$. But also, from eqs (5), (7), and (8) we have that $B(w)-D(w) \gtrless 0 \Leftrightarrow q / p \lesseqgtr Q(w)$. Therefore, since $B(w)-C(w) \gtreqless 0$ as $q / p \gtreqless Q(w)$, we have $q / p \gtreqless Q(w) \Leftrightarrow C(w) \gtrless B(w) \gtrless D(w)$, and the conditions stated in the proposition under which self-employment is preferred follow. The conditions under which entrepreneurship is preferred then follow.

Lemma 1 First we find from eq. (2) and eqs (6-7) that $\hat{l}_{p}>0 ; \hat{l}_{q}=0 ; \hat{l}_{w}<0 ; \hat{l}_{v}=0$; $B_{p}(w)<0 ; B_{q}(w)=0 ; \quad B_{w}(w)>0 ; B_{v}(w)<0 ; \quad C_{p}(w)=0 ; C_{q}(w)<0 ; \quad C_{w}(w)>$ $0 ; \quad C_{v}(w)<0 ; \quad D_{p}(w)<0 ; D_{q}(w)>0 ; \quad D_{w}(w)>0 ; D_{v}(w)=0 ; \quad \tilde{z}_{p}<0 ; \tilde{z}_{q}>0 ; \quad \tilde{z}_{w}>$ $0 ; \tilde{z}_{v}=0$. Using Proposition 1, we then specify the supply of individuals to wage employment and entrepreneurship:

$$
\begin{aligned}
& L^{s}= \begin{cases}\int_{\underline{y}}^{C} \int_{\underline{z}}^{\bar{z}} f(y, z) d z d y & \text { for } \quad q / p>Q(w) \\
\int_{\underline{y}}^{B} \int_{\underline{z}}^{\bar{z}} f(y, z) d z d y+\int_{B}^{C} \int_{\underline{z}}^{B} f(y, z) d z d y & \text { for } q / p<Q(w)\end{cases} \\
& E^{s}= \begin{cases}\int_{D}^{\underline{y}} \int_{\tilde{z}(y)}^{\underline{z}} f(y, z) d z d y & \text { for } q / p>Q(w) \\
\int_{B}^{C} \int_{B}^{\bar{z}} f(y, z) d z d y+\int_{C}^{\bar{y}} \int_{\tilde{z}(y)}^{\bar{z}} f(y, z) d z d y & \text { for } q / p<Q(w)\end{cases}
\end{aligned}
$$

Inserting $\hat{l}(A)$ into each double integral in $E^{S}$ we obtain labour demand, $L^{d}$. Using $A \equiv$ $\min (y, z)$, this can be written

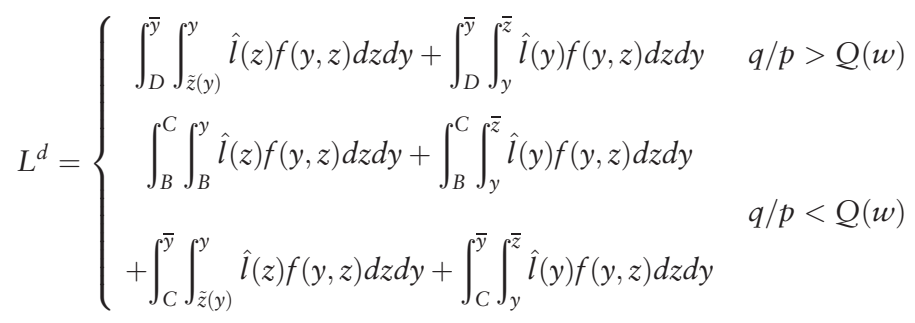

Differentiating $L^{s}$ and $L^{d}$ by $(p, q, w, v)$, the lemma is obtained. 
Proposition 2 From eq. (9), $w=\underline{w} \Rightarrow W=\emptyset ; w=\bar{w} \Rightarrow E=\emptyset$. Therefore, $L^{s}(\underline{w})=0$; $L^{d}(\bar{w})=0$. If $w=\underline{w}, U E(\bar{A}, \underline{w})>U S(\bar{A}) \Rightarrow E \neq \emptyset \Rightarrow L^{d}>0$; and if $w=\bar{w}, U W(\bar{w})>$ $U S(\bar{y}) \Rightarrow W \neq \emptyset \Rightarrow L^{s}>0$. It follows that if both $U E(\bar{A}, \underline{w})>U S(\bar{A})$ and $U W(\bar{w})>$ $U S(\bar{y})$, the excess demand functions satisfy $L^{d}(\underline{w})-L^{s}(\underline{w})>0$ and $L^{d}(\bar{w})-L^{s}(\bar{w})<0$. Then, by the continuity of $L^{d}-L^{S}$, there must exist a $w^{*} \in(\underline{w}, \bar{w})$ such that $L^{d}\left(w^{*}\right)-L^{s}\left(w^{*}\right)=0$. Additionally, if $w=\underline{w}$ then $U E(\underline{A}, \underline{w})<U S(\underline{A}) \Rightarrow S \neq \emptyset$, and if $w=\bar{w}$ then $U W(\bar{w})<U S(\bar{y}) \Rightarrow S \neq \emptyset$. The proposition follows.

Lemma 2 Writing labour supply and supply as $L^{s}(w, i)$ and $L^{d}(w, i)$, respectively, where $i=(p, q, v)$, when $w=w^{*}, d w / d i=\left(L_{i}^{d}-L_{i}^{s}\right) /\left(L_{w}^{s}-L_{w}^{d}\right)$. Using Lemma 1 with this equation yields $d w / d p>0, d w / d q \gtrless 0$, and $d w / d v>0$. Thus, (i) $d L / d p=L_{w}^{d}(d w / d p)+$ $L_{p}^{d}=\left(L_{p}^{d} L_{w}^{s}-L_{w}^{d} L_{p}^{s}\right) /\left(L_{w}^{s}-L_{w}^{d}\right)$; from Lemma $1, L_{w}^{d}-L_{w}^{s}<0$ and if $q / p>Q(w), L_{p}^{s}=0$ and the result for $d L / d p$ follows; (ii) $d L / d q=\left(L_{q}^{d} L_{w}^{s}-L_{w}^{d} L_{q}^{s}\right) /\left(L_{w}^{s}-L_{w}^{d}\right)<0$; (iii) $d L / d v=\left(L_{v}^{d} L_{w}^{s}-L_{w}^{d} L_{v}^{s}\right) /\left(L_{w}^{s}-L_{w}^{d}\right)$ and the result in the lemma follows.

\section{Borderline preferences with labour market segmentation}

To compare the utilities from the different activities we use eqs (11) and (12).

Self-employment versus wage employment. Since $w_{f}>w_{i}, U W_{f}>U W_{i}$. Thus, to consider first preferences, we compare $U S$ with $U W_{f}$. If the agent is rationed out of a formal job, second preferences matter, so we compare $U S$ with $U W_{i}$. Thus we obtain

$$
U S \gtrless U W_{j} \quad \text { as } \quad y \gtrless \frac{1}{q}\left(w_{j}-v\right) \equiv C\left(w_{j}\right), j=f, i
$$

Because $w_{f}>w_{i}, C\left(w_{f}\right)>C\left(w_{i}\right)$.

Entrepreneurship versus self-employment. As an entrepreneur, an individual chooses formality if $A>\tilde{A}$, but informality otherwise. This gives two comparisons with self employment:

$$
U E_{j} \gtrless U S \quad \text { as } \quad A \gtrless \frac{1}{p \hat{l}_{j}^{\alpha}}\left(q y+w_{j} \hat{l}_{j}\right) \equiv \tilde{z}_{j}(y), j=f, i
$$

As in Section 2, denote the fixed points of $\tilde{z}_{j}(y)$ as $D\left(w_{j}\right), j=f, i$; that is, $\tilde{z}_{j}\left(D\left(w_{j}\right)\right)=D\left(w_{j}\right)$.

Entrepreneurship versus wage employment. With respect to the agent's first preference, we compare $U E_{i}$ with $U W_{f}$, and if the agent is rationed out of a formal job, we compare $U E_{i}$ with $U W_{i}$ :

$$
U E_{i} \gtrless U W_{j} \quad \text { as } \quad A \gtrless \frac{1}{p l_{i}^{\alpha}}\left(w_{j}+w_{i} l_{i}-v\right) \equiv B\left(w_{i}, w_{j}\right), j=f, i
$$

where the first argument of $B(.,$.$) is the wage paid as an entrepreneur and the second argu-$ ment is the wage received as an employee.

We can now define corresponding values of $Q(.,$.$) . B\left(w_{i}, w_{j}\right)-C\left(w_{j}\right) \gtrless 0$ as $q / p \gtrless$ $Q\left(w_{i}, w_{j}\right)$,where

$$
Q\left(w_{i}, w_{j}\right) \equiv \frac{w_{j}-v}{l_{i}\left(w_{j}+w_{i} l_{i}^{\alpha}-v\right)}, j=f, i
$$

